\title{
French translation and validation of the Achilles Tendon Total Rupture Score "ATRS"
}

\author{
F. Buckinx ${ }^{\mathrm{a}, *}$, G. Lecoq ${ }^{\mathrm{b}}$, S. Bornheim ${ }^{\mathrm{b}, \mathrm{c}}$, J. Van Beveren ${ }^{\mathrm{d}}$, A. Valcu $^{\mathrm{e}}$, C. Daniel ${ }^{\mathrm{e}}$, \\ O. Bruyère ${ }^{\mathrm{a}}$, J.Y. Reginster ${ }^{\mathrm{a}, \mathrm{f}, 1}$, P. D’Hooghe ${ }^{\mathrm{g}}$, J.F. Kaux ${ }^{\mathrm{b}, \mathrm{c}}$ \\ a Department of Public Health, Epidemiology and Health Economics, WHO Collaborating Centre for Public Health Aspects of Musculoskeletal Health and \\ Ageing, University of Liège, Belgium \\ ${ }^{\mathrm{b}}$ Department of Sport Rehabilitation Sciences, University of Liège, Belgium \\ ${ }^{\mathrm{c}}$ Department of Physical Medicine and Rehabilitation, SportS, FIFA Medical Center of Excellence Liege University Hospital Center, Liege, Belgium \\ ${ }^{\mathrm{d}}$ Haute Ecole de la Province de Liège, Liège, Belgium \\ e Orthopaedic Surgery Department, University Hospital of Liège, Liege, Belgium \\ ${ }^{\mathrm{f}}$ Biochemistry Department, College of Science, King Saud University, Riyadh, Saudi Arabia \\ g Department of Orthopaedic Surgery, Aspetar Orthopaedic and Sports Medicine Hospital, FIFA Medical Centre of Excellence, Doha, Qatar
}

\section{A R T I C L E I N F O}

\section{Article history:}

Received 16 March 2019

Received in revised form 5 July 2019

Accepted 19 August 2019

\section{Keywords:}

ATRS

Achilles tendon rupture

Validation

Psychometric performances

\begin{abstract}
A B S T R A C T
Background: To provide a cross-cultural French adaptation of the Achille's Tendon Total Rupture Score (ATRS) and to assess its psychometric performances.

Method: The ATRS questionnaire was first translated and inter-culturally adapted into French according to international guidelines. Then, 95 subjects were recruited to complete the French version of the ATRS twice (2 weeks of interval). The SF-36 and VISA-A were used as comparative questionnaires. The psychometric properties of the questionnaire were evaluated (test-retest reliability, internal consistency, construct validity, floor/ceiling effects).

Results: Thetest-retest reliability was excellent (ICC of 0,966 (95\% Cl:0.644-0.879)) and the internal consistency very high (Cronbach's alpha of 0,98 ). The convergent and divergent construct validity were also confirmed. Finally, none of the subjects obtained the lowest score (0) or the maximal score (100) to the questionnaire.

Conclusion: A valid and reliable French version of the ATRS is now available.
\end{abstract}

(c) 2019 European Foot and Ankle Society. Published by Elsevier Ltd. All rights reserved.

\section{Introduction}

Patient Reported Outcome Measures (PROMs) are selfreported questionnaires that have become a cornerstone in evaluating the effectiveness of a treatment and patient's satisfaction [1]. In light of this, the Achilles Tendon Rupture Score (ATRS) has become an important tool in assessing functional outcomes following interventions among patients who have suffered from a complete Achilles tendon rupture [2]. The ATRS was first developed in 2007 and is a valid, reliable and sensitive questionnaire [3]. Originally developed in Swedish [3],

\footnotetext{
* Corresponding author at: University of Liège, Department of Public Health, Epidemiology and Health Economics, WHO Collaborating Centre for Public Health Aspects of Musculoskeletal Health and Ageing, CHU - Sart Tilman, Bât. B23, Quartier Hôpital, Avenue Hippocrate, 13, 4000 Liège, Belgium.

E-mail address: fanny.buckinx@uliege.b(F. Buckinx).

1 Representativa patient
}

previous studies performed a cross-cultural adaptation of the ATRS in various languages (i.e. Polish [4], Greek [5], Norwegian [1], Chinese [6], Turkish [7], Italian [8], Brazilian Portuguese [9], Persian [10], Dutch [11], Danish [12], British English [13]). To date, while French is the fifth most spoken language worldwide, there is no validated French instrument for measuring outcomes related to symptoms, function and physical activity after treatment of Achilles tendon ruptures. To fill this gap in the literature, the present study aimed to linguistically and crossculturally translate the ATRS into French and then to investigate its psychometric properties. Indeed, validity and reliability are population-specific and, if an instrument shows satisfactory properties in one population, there is no guarantee that it is appropriate for use in a culturally different population. Crosscultural adaptation of the ATRS for the French speaking population is warranted to facilitate comparison among studies at an international level but also to facilitate future research on the treatment of Achilles tendon rupture. 


\section{Methods}

\subsection{French translation and cross-cultural adaptation of the ATRS questionnaire}

The ATRS was translated according to the "Guidelines for the Process of Cross-Cultural Adaptation of Self-Report Measures", following 6 standardized steps, in order to achieve a linguistic and cultural equivalence between the original version and the translated version of the questionnaire [14].

\section{- Step 1: initial translation}

The first step was to translate the questionnaire from the original language (English) into the target language (French). Two bilingual translators (who are not part of the author team), both native French speakers, both with masters degrees (one of whom is an expert in the field of health and the other is unexperienced in this area) provided two independent translations (T1 and T2) of the original questionnaire.

\section{- Step 2: synthesis of the first two translations}

The second step was to combine the results of T1 and T2. Two translators and a recording observer (i.e. the main investigator) provide a single "version 1" of the translated questionnaire, taking into account any difficulties encountered when translating certain words or expressions.

\section{- Step 3: back translation}

The third step was to translate the version 1 back into the original language, to check that the translated version incorporated and respected the concepts of the original version. Two independent bilingual translators (one who was not part of the author team and XX), both native English speakers (one in the medical field and one outside the medical field), blinded to the original version of the questionnaire performed two independent backwards translations.

\section{- Step 4: expert committee}

The fourth step was to compare the backwards translations with the original questionnaire, in order to provide a "version 2" of the translated questionnaire, with semantic, idiomatic, experiential and conceptual equivalence. The expert committee, composed of one health professional (XXX), one expert in French language (XXX) and all the translators met to agree, by consensus, on a "version 2 " of the translated questionnaire. Indeed, the expert committee discussed the differences observed between the 2 versions of the questionnaire and reached agreement on the final version.

\section{- Step 5: pre-final version testing}

The fifth step was to test, using a group of 44 pathological subjects, the "version 2" of the questionnaire, to ensure good comprehension of each question (i.e. subjects understand how to answer the questionnaire alone) and conclude with a "version 3", the final version of the ATRS.

\section{- Step 6: expert committee approval}

The last step is the approval of the version 3 of the ATRS-French (ATRS-F) questionnaire, based on the information gathered from the previous steps (i.e., no difficulties answering the questionnaire and no misunderstanding or confusion with any item).

\subsection{Psychometric validation of the ATRS-F}

A validation phase was mandatory to ensure that the translation and use of the ATRS-F were reliable and valid. Therefore, an evaluation of its psychometric performances was carried out.

\subsubsection{Study population}

Pathological subjects, presenting with a diagnosis of Achilles tendon rupture, surgically and conservatively (i.e. non-surgically) treated, were recruited in the Physical Medicine and Rehabilitation Department of the University Hospital, in XXXXX. Patients surgically treated were recruited between the 3rd and the 12th month following their operation. Patients conservatively treated were recruited between the 3rd month and the 3rd year after their injury. The inclusion criteria were (1) to have Achilles tendon rupture that is clinically diagnosed by an orthopedic surgeon, (2) to be aged between 20 and 70 years old, (3) to speak and understand French. Bilateral rupture of the Achilles tendon was an exclusion criterion.

Healthy subjects (i.e. not suffering from Achilles tendon rupture) were recruited in Liège via social media. To be included in this study, subjects need to be aged between 20 and 70 years old and have no history of Achilles tendon rupture.

The people who took part in the study were informed of the objectives pursued and gave their oral consent to participate. After consultation of our institution's Ethics Committee, an ethics approval was not required as per applicable institutional and national guidelines and the informed consent of the participants was implied through survey completion. On the other hand, an informational note on the use and processing of data was attached.

\subsubsection{Study organization and instruments}

Once the ATRS translation was carried out according to the international guidelines (Guidelines for the Process of Cross-Cultural Adaptation of Self-Report Measures), the translated questionnaire was submitted to all subjects (i.e. surgically and non-surgically treated for Achilles tendon rupture and healthy population) between October 2017 and April 2018. Each subject was asked to answer the ATRS questionnaire twice, within 2 weeks, in order to evaluate the testretest reliability. In addition, all participants in the study were asked to answer two additional questionnaires, the VISA-A (The Victorian Institute of Sport Assessment) and the SF-36, validated in French [15]. The used of these additional questionnaires made it possible to establish correlations between various items that also measure subjects' quality of life.

\section{- ATRS \\ questionnaire}

The ATRS is a self-reported questionnaire composed of ten items that reflects the opinion of patients regarding their symptoms, limitations in daily activities and physical activities after a complete rupture of the Achilles tendon. At the end of each question, the patient is given a scale from 0 to 10 , where 0 corresponds to worse symptoms and greater limitations of physical activity, and 10 indicates no symptoms and limitations. The final score is obtained by the sum of the answers of each item. The ATRS total score ranges from 0 to 100 , with higher scores equal to less symptoms and limitations $[3,9]$. Previous validation studies of the ATRS questionnaire were performed up to 3 years after the injury. Therefore, the ATRS the questionnaire allows the follow-up of patients until this deadline.

- VISA-A (The Victorian Institute of Sport Assessment) questionnaire

The Victorian Institute of Sport Assessment-Achilles tendinopathy questionnaires (VISA-A) is a self-administered questionnaire 
assessing the symptoms of Achilles tendinopathies and their impact upon physical activity [16]. It has been validated in French and consists of eight questions split into three categories, the first three focusing on pain, the next three on the functional consequences of Achilles tendinopathies and the last two on the consequences for sporting activity [17].
- The SF-36 questionnaire

The Short-Form 36 questionnaire (SF-36) is a 36-item questionnaire that measures quality of life (QoL) across eight domains, both physical and emotional. The eight domains that the SF-36 measures are as follows: physical functioning, role

\section{ATRS-F}

(Achilles Tendon Total Rupture Score)

Toutes les questions concernent les limitations/difficultés liées à votre blessure au tendon d'Achille.

Répondez à chacune des questions en notant vos limitations/symptômes sur une échelle de 0 à 10 .

Pour rappel : 0 = limitation sévère et 10 = aucune limitation.

Merci d'entourer le nombre qui correspondent à votre niveau de limitation

1- Etes-vous limité(e) en raison d'une perte de force dans le mollet/ tendon d'Achille/pied?

(limitation sévère) 012345678910 (Aucune limitation)

2- Etes-vous limité(e) en raison d'une fatigue dans le mollet/tendon d'Achille/pied ?

(limitation sévère) 012345678910 (Aucune limitation)

3- Etes-vous limité(e) en raison d'une raideur dans le mollet/ tendon d'Achille/pied?

(limitation sévère) 012345678910 (Aucune limitation)

4- Etes-vous limité(e) en raison d'une douleur dans le mollet/ tendon d'Achille/pied?

(limitation sévère) 012345678910 (Aucune limitation)

5- Etes-vous limité(e) dans les activités de la vie quotidienne?

(limitation sévère) 012345678910 (Aucune limitation)

6- Etes-vous limité(e) en marchant sur des surfaces irrégulières?

(limitation sévère) 012345678910 (Aucune limitation)

7- Etes-vous limité(e) lorsque vous montez rapidement les escaliers ou une côte?

(limitation sévère) 012345678910 (Aucune limitation)

8- Etes-vous limité(e) lors d'activités incluant de la course à pied?

(limitation sévère) 012345678910 (Aucune limitation)

9- Etes-vous limité(e) lors d’activités incluant du saut ?

(limitation sévère) 012345678910 (Aucune limitation)

10- Etes-vous limité(e) en effectuant un travail physique intense ?

(limitation sévère) 012345678910 (Aucune limitation) 
limitations due to physical health, role limitations due to emotional problems, energy/fatigue, emotional well-being, social functioning, pain and general health. In summary, an aggregate percentage score is produced for each of the eight domains that the SF-36 measures. The percentage scores range from $0 \%$ (lowest or worst possible level of functioning) to $100 \%$ (highest or best possible level of functioning) [18].

\subsubsection{Assessment of the test-retest reliability}

This is the evaluation of the stability of the scale over time using the intra-class correlation coefficient (ICC) and 95\% confidence interval. When no health change was observed among individuals, the score of the ATRS-F was expected to be unchanged. The patients completed the questionnaire twice, within a 14 day interval, while the subjects' status remained unchanged. Note that a single investigator evaluated the health status of the subjects at baseline and after 14 days. During the 14 days, patients were not engaged in rehabilitation, nor did they receive any treatment that could affect their condition. The closer the coefficient is to 1 , the higher the reliability. An ICC over 0.7 was considered indicative of acceptable reliability [19]. To complete this result, the Standard Error of Measurement (SEM) was calculated by first creating a variable for the difference between the score obtained during the first and the second administration (test score-retest score = difference). Next, we calculated the standard deviation of difference in our sample ( $S D$ difference) and divided the obtained value by the square root of $2(\mathrm{SEM}=\mathrm{SD}$ difference $/ \sqrt{ } 2)$. The Minimal Detectable Change was calculated with the formula $(\mathrm{MDC}=1.96 \times \sqrt{ } 2 \times \mathrm{SEM})$ [20].

\subsubsection{Assessment of the construct validity}

The construct validity was investigated by measuring two components: convergent and divergent validity. The correlation between the F-AKPS and other questionnaires or domains of questionnaires which have similar dimensions (convergent validity) or different dimensions (divergent validity) was assessed. The assessment of this psychometric property was based on two hypotheses: (1) there is a strong correlation between the score of the ATRS-F and subscales of the VISA-A and the SF-36 regarding the evaluation of similar concepts (i.e. convergent validity); (2) there is a weak correlation between the score of the ATRS-F and subscales of the VISA-A and the SF-36 regarding the evaluation of different concepts (i.e. divergent validity).

\subsubsection{Assessment of internal consistency}

Internal consistency is the estimation of homogeneity across items. Cronbach's alpha coefficient assesses the internal consistency of a set of items, scale or subscale, corresponding to a single clinical dimension. The aim is to estimate the strength of the intercorrelations between items. The value of alpha varies between 0 and 1, with the internal consistency increasing as alpha approaches 1. A coefficient value greater than 0.70 indicates a high level of internal consistency [12]. Spearman correlations between the total ATRS-F score and each individual item was also calculated to further test this psychometric performance. A correlation above 0.6 is considered as relevant (strong correlation) [21].

\subsubsection{Assessment of floor and ceiling effects}

Floor and ceiling effects were defined when at least $15 \%$ of the population obtains the lowest (floor effect) or the highest score (ceiling effect) to the questionnaire [19]. When either of these effects are present, subjects with a minimum or a maximum score cannot be distinguished from each other, decreasing the discriminative power of the questionnaire.

The priori hypothesis is that the ATRS-F will have good psychometric properties, just as the other versions of the questionnaire have.

\subsection{Statistical analysis}

Normality of quantitative variables was tested by the ShapiroWilk test. According to this test, quantitative variables were expressed as mean $\pm S D$ whereas qualitative variables were reported as absolute and relative frequencies (\%). Reliability has been measured by Cronbach's alpha coefficient to test the internal consistency and ICC to test the reliability between the first and the retest scores of the ATRS-F questionnaire. Finally, Spearman's correlations were used to evaluate the construct validity of the ATRS-F questionnaire and therefore, to measure the correlations between the ATRS-F questionnaire and SF-36 and VISA-A. Analyses were performed using SPSS Statistics 24 software (IBM, Armonk, New-York, USA). Results were considered statistically significant at the $5 \%$ critical level $(\mathrm{p}<0.05)$.

\section{Results}

\subsection{French translation of the ATRS questionnaire}

Based on the procedure detailed above, the ATRS was Frenchtranslated without any difficulties. A few semantic differences between the translations $\mathrm{T} 1$ and $\mathrm{T} 2$ were observed and were resolved during analysis of the two translations. No major issues were observed during the back translations and the versions obtained were very similar to the original English version. The prefinal version of the ATRS-F was tested by 10 subjects ( 5 pathological subjects and 5 healthy subjects), who were

Table 1

Comparison of the obtained scores for the different translation.

\begin{tabular}{|c|c|c|c|c|c|c|}
\hline & \multicolumn{4}{|c|}{ Score of the pathologic population } & \multicolumn{2}{|c|}{ Score of the healthy population } \\
\hline & $\mathrm{n}$ & Test & $\mathrm{n}$ & Re-test & $\mathrm{n}$ & Test \\
\hline French version & 44 & $65.09 \pm 21.84$ & 44 & $67.07 \pm 20.49$ & 51 & 100 \\
\hline Original version [3] & 43 & $77 \pm 21.4$ & & 1 & 52 & $99.8 \pm 1.1$ \\
\hline Polish version [4] & 71 & $87.4 \pm 14$ & & i & & 1 \\
\hline Greek version [5] & 46 & $84.1(34-100)$ & & i & & i \\
\hline Norwegian version [1] & 94 & $87(16-100)$ & & i & & 1 \\
\hline Chinese version [6] & 112 & $57.4 \pm 13.2$ & & 1 & & 1 \\
\hline Turkish version [7] & 74 & $78.1 \pm 23.1$ & 74 & $79.1 \pm 22.5$ & & i \\
\hline Italian version [8] & 80 & $68.5 \pm 25.1$ & & 1 & & i \\
\hline Brazilian portuguese version [9] & 46 & $94.3 \pm 5.9$ & 46 & $93.8 \pm 6.1$ & & \\
\hline Persian version $[10]$ & 30 & $39.5 \pm 25.3$ & 30 & $40.2 \pm 25.4$ & & $84.9 \pm 18.5$ \\
\hline Dutch version [11] & 103 & 1 & 75 & 1 & & 1 \\
\hline Danish version [12] & 52 & $70 \pm 22$ & 52 & $73 \pm 22$ & & \\
\hline British english version [13] & 81 & $57 \pm 24.7$ & 81 & $56 \pm 25.7$ & & \\
\hline
\end{tabular}


subsequently integrated into the validation step. None of these subjects expressed any difficulties understanding the questionnaire's various items or had particular difficulty to complete the questionnaire. The Expert Committee gave their approval to this pre-final version of the questionnaire that became the definitive finale version ATRS-F (Fig. 1)

\subsection{Psychometric validation of the ATRS-F}

\subsubsection{Description of the population}

The total study sample for ATRS-F validation step consisted of 95 subjects (44 pathological subjects and 51 healthy subjects). Among the pathological subjects, 30 were surgically treated for Achilles tendon rupture whereas 14 patients were conservatively treated (i.e. non-surgically). The mean age of the general population was $34.41 \pm 12.88$ years old and was $37.50 \pm 13.8$ years old in the pathological group and $31.75 \pm 11.47$ years old in the healthy group $(\mathrm{p}=0.03)$. In the total population, $64.2 \%$ were men, and was respectively $72.7 \%$ and $56.9 \%$ in the pathological and the healthy group. All participants were athletes and the most represented sports were soccer (29\% in the pathological group and $14 \%$ in the healthy group) and running (16\% in both groups). Total scores of the different versions of the ATRS are presented in Table 1. The total score obtained for the different translation, in previous studies, are close to those obtained with the ATRS-F.

\subsubsection{Test-retest reliability}

Excellent test-retest reliability was found, with an overall Intraclass Correlation Coefficient (ICC) of 0.996 (95\% CI : $0.934-$ $0.982)$. As shown in Table 2, the ICC ranged between 0.789 (95\%CI : $0.644-0.879$ ) (item 1) and 0.967 (95\%CI : 0.940-0.982) (item 10) for individual items of the questionnaire. All the ICC are above 0.7 and are therefore considered as acceptable reliability.

\subsubsection{Construct validity}

Regarding the convergent validity, the ATRS-F total score was significantly correlated with the VISA-A total $(\mathrm{r}=0.621, \mathrm{p}<0.0001)$ and with some domains of the SF-36 which have similar dimensions, such as physical functioning, role limitation due to physical problem, bodily pain and general health ( $\mathrm{r}$ ranged between 0.604 and $0.848 ; \mathrm{p}<0.001$ ).

Regarding the divergent validity, the ATRS-F total score was weakly correlated or not correlated with the domains of the SF-36 which have different dimensions, such as mental health $(r=0.07$, $\mathrm{p}=0.652)$, emotional role $(\mathrm{r}=0.146, \mathrm{p}=0.345)$, social function $(\mathrm{r}=0.361, \mathrm{p}<0.05)$ and vitality $(\mathrm{r}=0.392, \mathrm{p}<0.05)$.

Results of construct validity are available in Table 3.

\subsubsection{Internal consistency}

As indicated by the ATRS-F Cronbach's alpha, which is 0.98 , an excellent level of consistency was observed. Moreover, Cronbach's

Table 2

Test-restest reliability of the ATRS-F.

\begin{tabular}{lll}
\hline & Intraclass Correlation Coefficient (ICC) & $95 \% \mathrm{CI}$ \\
\hline Item 1 & 0.789 & $0.644-0.879$ \\
Item 2 & 0.835 & $0.717-0.906$ \\
Item 3 & 0.838 & $0.722-0.908$ \\
Item 4 & 0.845 & $0.733-0.912$ \\
Item 5 & 0.942 & $0.897-0.968$ \\
Item 6 & 0.915 & $0.849-0.953$ \\
Item 7 & 0.862 & $0.762-0.923$ \\
Item 8 & 0.957 & $0.923-0.976$ \\
Item 9 & 0.955 & $0.919-0.975$ \\
Item 10 & 0.967 & $0.940-0.982$ \\
Total & 0.966 & $0.934-0.982$ \\
\hline
\end{tabular}

In our sample, $\mathrm{SEM}=2.58$ points and $\mathrm{MDC}$ (ind) $=7.16$ points. alpha values vary between 0.91 and 0.98 for each item of the questionnaire. All items of the questionnaire were positively and significantly correlated with the total score of the ATRS-F, with Spearman correlation ranging from $r=0.82$ (item 2) to $r=0.96$ (item 9) (Table 4).

\subsubsection{Floor and ceiling effects}

None of the pathological subjects obtained the lowest score (0) or the maximal score (100) on the questionnaire. Therefore, no floor neither ceiling effects were found for the questionnaire.

\section{Discussion}

The main finding of the present study is that, after following standardized translation and cross-cultural adaptation processes, the final French version of the ATRS shows adequate validity and reliability. The questionnaire can therefore be used in the Frenchspeaking countries to assess clinical results in patients sustaining Achilles tendon rupture. No major difficulties were encountered during the translation process and the expert committee considered the final ATRS-F equivalent to the English version.

The total score obtained for the different translation, in previous studies, was close to the score obtained with the ATRS-F. The slight differences observed could be explained by the characteristics of the population. Indeed, our subjects are younger $(34.4 \pm 12.8$ years old) than those included in other studies $(45.3 \pm 8.5$ years old in Norway, $42.6 \pm 8$ years old in Poland, $44.5 \pm 9.7$ years old in China). Moreover, the proportion of men in our sample $(64 \%)$ is lower compared to other countries (95\% in Norway, $71 \%$ in Poland, $92.8 \%$ in China, $94.7 \%$ in Brazil, $73.8 \%$ in Dutch). Finally, we recruited patients surgically treated between the 3rd and the 12th month following their operation. Patients conservatively treated were recruited between the 3rd month and the 3rd year after their injury. These delays are somewhat variable between studies (for example, 20 months after the rupture in Dutch, between 6 and 64 months after surgery in Poland).

Regarding the psychometric properties, the ATRS-F questionnaire showed excellent test-retest reliability and therefore excellent stability over time, since the ICC of the total score was 0.966. In case of clinical use, the ICC should be greater than 0.9 to indicate a high test reliability [10]. The ICC found in this study is close to that observed in the original version of the ATRS (ICC $=0.98)$ and corroborates those observed with the Polish $($ ICC $=0.90)$ [4], Greek $($ ICC $=0.97)$ [5], Norwegian $($ ICC $=0.90)$ [1], Chinese $(I C C=0.986)$ [6], Turkish [7], Italian $(I C C=0.93)$ [8], Brazilian Portuguese (ICC $=0.93)$ [9], Persian $($ ICC $=0.98)$ [10], Dutch $(I C C=0.852)$ [11], Danish $($ ICC $=0.908)$ [12] and English $($ ICC $=0.98)$ [13] versions of the ATRS. The few differences observed across the studies could probably be explained by the time interval between tests and retests. Moreover, the precision of the measurement was calculated using MDC and SEM. It is accepted that a SEM variability of a measure lower than $10 \%$ could be considered appropriate for clinical purposes [22]. We are below this threshold because our SEM was 2.58 points (total score ranged between 0 and 100 points)

We observed excellent construct validity (i.e. convergent and divergent). We performed analyses showed that the ATRS-F was strongly and significantly correlated with the VISA-A questionnaire and the physical functioning subscores of the SF-36 questionnaire. A correlation of $r=0.621$ with the VISA-A questionnaire is observed and is close to that obtained with the Italian and Swedish adaptations of the ATRS ( $r=0.72$ and $r=0.78$, respectively). It is considered as relevant because the instrument measures pain, symptoms and physical activity aspects among patients with chronic Achilles tendinopathy [17]. Therefore, the VISA-A questionnaire also contains items which are not appropriate for 
Table 3

Construct validity of the ATRS.

\begin{tabular}{|c|c|c|}
\hline ATRS vs. & Spearman correlation (r) & p-value \\
\hline \multicolumn{3}{|l|}{ Convergent validity } \\
\hline VISA-A Total Score & 0.621 & $\mathrm{p}<0.001$ \\
\hline $\begin{array}{l}\text { SF-36 } \\
\text { physical functioning }\end{array}$ & 0.706 & $\mathrm{p}<0.001$ \\
\hline $\begin{array}{l}\text { SF-36 } \\
\quad \text { role limitation due to physical problem }\end{array}$ & 0.604 & $\mathrm{p}<0.001$ \\
\hline $\begin{array}{l}\text { SF-36 } \\
\text { bodily pain }\end{array}$ & 0.848 & $\mathrm{p}<0.001$ \\
\hline $\begin{array}{l}\text { SF-36 } \\
\text { general health }\end{array}$ & 0.639 & $\mathrm{p}<0.001$ \\
\hline \multicolumn{3}{|l|}{ Divergent validity } \\
\hline $\begin{array}{l}\text { SF-36 } \\
\text { emotional role }\end{array}$ & 0.146 & 0.345 (NS) \\
\hline SF-36 Vitality & 0.392 & $\mathrm{p}<0.05$ \\
\hline $\begin{array}{l}\text { SF-36 } \\
\text { mental health }\end{array}$ & 0.070 & 0.652 (NS) \\
\hline $\begin{array}{l}\text { SF-36 } \\
\quad \text { social function }\end{array}$ & 0.361 & $\mathrm{p}<0.05$ \\
\hline
\end{tabular}

Table 4

Internal consistency of the ATRS-F.

\begin{tabular}{lll}
\hline & Spearman correlation $(\mathrm{r})$ & Cronbach alpha coefficient \\
\hline Item 1 & 0.94 & 0.96 \\
Item 2 & 0.82 & 0.91 \\
Item 3 & 0.90 & 0.91 \\
Item 4 & 0.86 & 0.91 \\
Item 5 & 0.86 & 0.97 \\
Item 6 & 0.86 & 0.95 \\
Item 7 & 0.95 & 0.92 \\
Item 8 & 0.92 & 0.97 \\
Item 9 & 0.96 & 0.97 \\
Item 10 & 0.95 & 0.98 \\
Score total & 0.98 & \\
\hline
\end{tabular}

patients with acute Achilles tendon rupture. Nevertheless, this tool was used as it was previously validated in French [17].

Furthermore, a strong internal consistency was observed (Cronbach's alpha of 0.98). The items are therefore very sensitive to the concepts being evaluated and there is no redundancy between items in the questionnaire. This result is comparable to the original version (Cronbach's alpha of 0.96). Moreover, other ATRS studies also found strong internal consistency, with Cronbach's alpha ranging from 0.89 [6] to 0.97 [8].

Finally, there is evidence that instruments with good content validity have low ceiling and floor effects [23]. This is the case with our study because none of the pathological patients achieved the minimum or the maximum scores. This is consistent with the other translated versions of the ATRS since none of them found floor effect $[1,4,6,7,10,11]$. Ceiling effects were found only in Dutch, Turkish and Norwegian versions (i.e. Respectively $7.8 \%, 14 \%$ and $6.4 \%$ of the subjects achieve the maximum score). However, these percentages are still below the cut-off point of $15 \%$ which is considered as relevant. Note that floor/ceiling effects have not been measured in Danish [12], Brazilian Portuguese [9], Italian [8], Greek [5] and British English versions [13].

We acknowledge some potential limitations in this study. The first limitation concerns the external validity of our results. The total sample tested in this study consisted of 95 athletes (64\% of men) from Liège, aged $34.41 \pm 12.88$ years old, so they are not entirely representative of the French-speaking population. However, the population is quite similar to those included in the original study during the development of ATRS or in the other ATRS validation studies in other languages, except the Polish version. In the latter, only men were included. Moreover, the patients enrolled in the present study were at different stages of rehabilitation (patients surgically treated were recruited between the 3rd and the 12th month following their operation and patients conservatively treated were recruited between the 3rd month and the 3rd years after their injury). The stage of rehabilitation could have influenced the reliability data, because the more the subjects are advanced in their rehabilitation, the more likely there will be a change in conditions between the two tests. Another weakness could be in our recruitment method: controls subjects were recruited via social media. This introduces a selection bias by potentially overrepresenting those individuals who spend the most amount of time on social media communities. Another concern with the control group was that patients with clinical complaints of Achilles tendinopathy were not excluded. This may have introduced a recruitment bias.

The second limitation concerned the responsiveness, or sensitivity to change, that could not be measured in our study given its cross-sectional design and because all subjects reported no change in their health status (i.e. to assess the test-retest reliability). This assessment is however essential in other contexts, for example, in assessing therapeutic intervention. This could bring additional values into our psychometric validation. Cui et al. highlighted a great responsiveness for the Chinese version of the ATRS, as the absolute values of Effect Size (ES) and Standard Response Mean (SRM) were 1.01 and 4.81 [6]. This data needs to be confirmed for the French version of the ATRS.

Overall, the results of this research, highlighted that the French version of the ATRS is valid and reliable, are similar to previous adaptations of the ATRS.

\section{Conclusion}

A valid and reliable French version of the ATRS is now available and can be used to assess symptoms, function and physical activity after treatment in patients with a total Achilles tendon rupture. With this study, we validated the ATRS for French speakers and this version demonstrated adequate psychometric properties. Further studies are still needed to determine the responsiveness of the French version of the ATRS.

\section{Conflict of interest}

None. 


\section{References}

[1] Myhrvold SB, Sandnes O, Hoelsbrekken SE. Validity and reliability of the norwegian translation of the achilles tendon total rupture score. Knee Surg Sports Traumatol Arthrosc 2018;26(7):2045-50.

[2] Bhatia RASSM. Acute Achilles tendon rupture treatment: where are we now? J Arthrosc Jt Surg 2018;5(3):139-44.

[3] Nilsson-Helander K, Thomee R, Silbernagel KG, Thomee P, Faxen E, Eriksson BI, Karlsson J. The achilles tendon total rupture score (ATRS): development and validation. Am J Sports Med 2007;35(3):421-6.

[4] Bakowski P, Rubczak S, Wolff-Stefaniak M, Grygorowicz M, Piontek T. Reliability and validity of the polish version of the achilles tendon total rupture score. Knee Surg Sports Traumatol Arthrosc 2018;26(7):2074-9.

[5] Touzopoulos P, Ververidis A, Giakas G, Drosos GI. Validation and cross-cultural adaptation of Greek version of Achilles Tendon Total Rupture Score. Foot Ankle Surg 2017;25(1):8-12.

[6] Cui J, Jia Z, Zhi X, Li X, Zhai X, Cao L, Weng W, Zhang J, Wang L, Chen X, Su J. The chinese version of achilles tendon total rupture score: cross-cultural adaptation, reliability and validity. Health Qual Life Outcomes 2017;15(1):2.

[7] Kaya Mutlu E, Celik D, Kilicoglu O, Ozdincler AR, Nilsson-Helander K. The Turkish version of the Achilles Tendon Total Rupture Score: cross-cultural adaptation, reliability and validity. Knee Surg Sports Traumatol Arthrosc 2015;23(8):2427-32.

[8] Vascellari A, Spennacchio P, Combi A, Grassi A, Patella S, Bisicchia S, Canata GL, Zaffagnini S. Cross-cultural adaptation and multi-centric validation of the Italian version of the Achilles Tendon Total Rupture Score (ATRS). Knee Surg Sports Traumatol Arthrosc 2018;26(3):854-61.

[9] Zambelli R, Pinto RZ, Magalhaes JM, Lopes FA, Castilho RS, Baumfeld D, Dos Santos TR, Maffulli N. Development of the Brazilian Portuguese version of the Achilles Tendon Total Rupture Score (ATRS BrP): a cross-cultural adaptation with reliability and construct validity evaluation. BMC Sports Sci Med Rehabil 2016;8:11.

[10] Ansari NN, Naghdi S, Hasanvand S, Fakhari Z, Kordi R, Nilsson-Helander K. Cross-cultural adaptation and validation of persian achilles tendon total rupture score. Knee Surg Sports Traumatol Arthrosc 2016;24(4):1372-80.

[11] Opdam KTM, Zwiers R, Wiegerinck JI, Kleipool AEB, Haverlag R, Goslings JC, van Dijk CN. Reliability and validation of the Dutch Achilles Tendon
Total Rupture Score. Knee Surg Sports Traumatol Arthrosc 2018;26 (3):862-8.

[12] Ganestam A, Barfod K, Klit J, Troelsen A. Validity and reliability of the Achilles Tendon Total Rupture Score. J Foot Ankle Surg 2013:52(6):736-9.

[13] Carmont MR, Silbernagel KG, Nilsson-Helander K, Mei-Dan O, Karlsson J, Maffulli N. Cross cultural adaptation of the Achilles Tendon Total Rupture Score with reliability, validity and responsiveness evaluation. Knee Surg Sports Traumatol Arthrosc 2013;21(6):1356-60.

[14] Beaton DE, Bombardier C, Guillemin F, Ferraz MB. Guidelines for the process of cross-cultural adaptation of self-report measures. Spine (Phila Pa 1976) 2000;25(24):3186-91.

[15] Leplege A, Ecosse E, Verdier A, Perneger TV. The French SF-36 Health Survey: translation, cultural adaptation and preliminary psychometric evaluation. J Clin Epidemiol 1998;51(11):1013-23.

[16] Robinson JM, Cook JL, Purdam C, Visentini PJ, Ross J, Maffulli N, Taunton JE Khan KM. The VISA-A questionnaire: a valid and reliable index of the clinical severity of Achilles tendinopathy. Br J Sports Med 2001;35(5):335-41.

[17] Kaux JF, Delvaux F, Oppong-Kyei J, Dardenne N, Beaudart C, Buckinx F, Croisier JL, Forthomme B, Crielaard JM, Bruyere O. Validity and reliability of the French translation of the VISA-A questionnaire for Achilles tendinopathy. Disabil Rehabil 2016;38(26):2593-9.

[18] Ware Jr.JE, Sherbourne CD. The MOS 36-item short-form health survey (SF-36). I Conceptual framework and item selection. Med Care 1992;30(6):473-83.

[19] Terwee CB, Bot SD, de Boer MR, van der Windt DA, Knol DL, Dekker J, Bouter LM, de Vet HC. Quality criteria were proposed for measurement properties of health status questionnaires. J Clin Epidemiol 2007;60(1):34-42.

[20] Weir JP. Quantifying test-retest reliability using the intraclass correlation coefficient and the SEM. J Strength Cond Res 2005;19(1):231-40.

[21] Akoglu H. User's guide to correlation coefficients. Turk J Emerg Med 2018;18 (3): $91-3$.

[22] Cejudo A, Sainz de Baranda P, Ayala F, Santonja F. Test-retest reliability of seven common clinical tests for assessing lower extremity muscle flexibility in futsal and handball players. Phys Ther Sport 2015;16(2):107-13.

[23] Fermanian J. Validation of assessment scales in physical medicine and rehabilitation: how are psychometric properties determined? Ann Readapt Med Phys 2005;48(6):281-7. 